Acta Crystallographica Section E

Structure Reports

Online

ISSN 1600-5368

Graham Smith, ${ }^{\text {a* }}$ Urs D. Wermuth $^{a}$ and Peter C. Healy ${ }^{b}$

${ }^{a}$ Centre for Instrumental and Developmental Chemistry, Queensland University of Technology, GPO Box 2434, Brisbane 4001, Australia, and ${ }^{\mathbf{b}}$ School of Science, Griffith University, Nathan 4111, Australia

Correspondence e-mail: g.smith@qut.edu.au

Key indicators

Single-crystal X-ray study

$T=295 \mathrm{~K}$

Mean $\sigma(\mathrm{C}-\mathrm{C})=0.006 \AA$

$R$ factor $=0.056$

$w R$ factor $=0.217$

Data-to-parameter ratio $=14.6$

For details of how these key indicators were automatically derived from the article, see http://journals.iucr.org/e.

\section{The 1:1 proton-transfer compound of benzylamine with 3,5-dinitrosalicylic acid}

The crystal structure of the proton-transfer compound from the reaction of 3,5-dinitrosalicylic acid (DNSA) with benzylamine (BA), viz. benzylammonium 3,5-dinitrosalicylate, $\mathrm{C}_{7} \mathrm{H}_{10} \mathrm{~N}^{+} \cdot \mathrm{C}_{7} \mathrm{H}_{3} \mathrm{~N}_{2} \mathrm{O}_{7}{ }^{-}$, shows a hydrogen-bonded polymer in which the protonated primary amine group of benzylamine gives a total of six inter-species interactions with $\mathrm{O}$ atoms of the DNSA anions. In addition, there are unusual centrosymmetric interactions between the carboxylate groups of the DNSA anions.

\section{Comment}

3,5-Dinitrosalicylic acid (DNSA) has proved to be the best of the nitro-substituted aromatic carboxylic acids for the construction of stable hydrogen-bonded cocrystalline solids. As well as giving a number of neutral crystalline polymorphic solvate systems (Smith et al., 1995; Kumar et al., 1999), a total of 20 proton-transfer compounds with both aromatic and aliphatic amines have been synthesized and characterized crystallographically (Smith et al., 2001, 2002). With the exception of the 1:2 adduct with 4-aminobenzoic acid (Smith et al., 1995), all of these are 1:1 compounds. To investigate the effect of the presence of an aromatic substituent group on the interactive behaviour of the primary amine moiety in reactions with DNSA, the mixed aromatic substituted aliphatic amine benzylamine (BA) was investigated. This resulted in crystals of the title compound, benzylammonium 3,5-dinitrosalicylate, $(\mathrm{BA})^{+}(\mathrm{DNSA})^{-},(\mathrm{I})$.

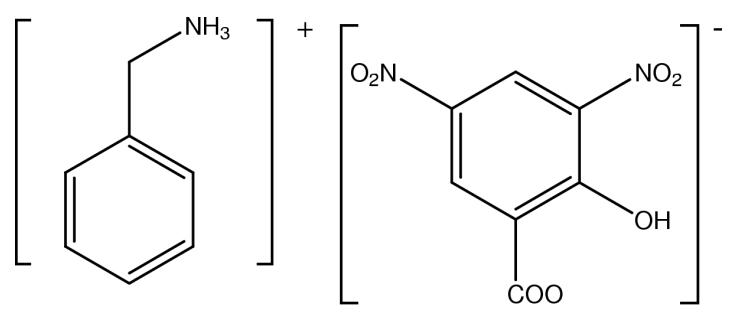

(I)

The structure determination of (I) has shown that the primary amine group of benzylamine is protonated (Fig. 1), giving a hydrogen-bonded network polymer in which all three $\mathrm{H}$ atoms are involved in six associations (all three-centre) with DNSA O-atom acceptors [carboxylate (O71 and O72), phenolate (O2) and nitro (O31 and O32): N...O 2.823 (6)3.239 (7) A] (Table 1). The usual intramolecular hydrogen bond is found between the phenolic $\mathrm{O}$ atom and the antirelated $\mathrm{H}$ atom on the carboxyl group $[\mathrm{O} 72-\mathrm{H} 72 \cdots \mathrm{O} 2$ 2.483 (6) $\AA$ ], compared with the mean of $2.46 \AA$ for the current series (Smith et al., 2002). An unusual centrosym-
Received 12 June 2002 Accepted 9 July 2002 Online 19 July 2002 
metric intermolecular association is also found between the carboxylate groups of the DNSA anions [O72- $\mathrm{H} 72 \cdots \mathrm{O} 72^{\mathrm{i}}$ $2.814(6) \AA$ and $\mathrm{O}-\mathrm{H} \cdots \mathrm{O}^{\mathrm{i}} 101(5)^{\circ}$ : symmetry code: (i) $2-x$, $2-y, 1-z]$. The centrosymmetric stacks of DNSA anions forming down the $a$-cell direction are linked into polymer sheets by parallel rows of BA cations (Fig. 2). As found with other examples of these DNSA salts, significant $\pi-\pi$ interaction between the DNSA anions in the stacks is in evidence.

\section{Experimental}

The synthesis of the title compound, (I), was carried out by heating under reflux for $10 \mathrm{~min}$, using $1 \mathrm{mmol}$ quantities of 3,5-dinitrosalicylic acid and benzylamine in $50 \mathrm{ml}$ of $80 \%$ ethanol/water. After concentration to $c a 30 \mathrm{ml}$, partial room-temperature evaporation of the hotfiltered solution gave crystals suitable for X-ray crystallography.

\section{Crystal data}

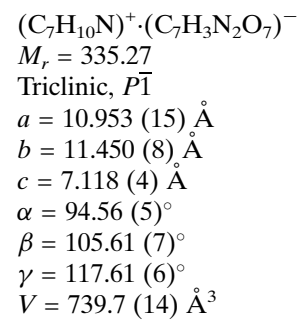

$$
\begin{aligned}
& Z=2 \\
& D_{x}=1.505 \mathrm{Mg} \mathrm{m}^{-3} \\
& \text { Mo } K \alpha \text { radiation } \\
& \text { Cell parameters from } 25 \\
& \quad \text { reflections } \\
& \theta=12.6-17.1^{\circ} \\
& \mu=0.12 \mathrm{~mm}^{-1} \\
& T=295(2) \mathrm{K} \\
& \text { Block, yellow } \\
& 0.30 \times 0.25 \times 0.20 \mathrm{~mm}
\end{aligned}
$$

\section{Data collection}

Rigaku AFC-7 $R$ diffractometer $\omega-2 \theta$ scans

Absorption correction: none 3872 measured reflections 3406 independent reflections 1708 reflections with $I>2 \sigma(I)$ $R_{\text {int }}=0.027$

$$
\begin{aligned}
& \theta_{\max }=27.5^{\circ} \\
& h=-14 \rightarrow 6 \\
& k=-13 \rightarrow 14 \\
& l=-8 \rightarrow 9 \\
& 3 \text { standard reflections } \\
& \quad \text { every } 150 \text { reflections } \\
& \quad \text { intensity decay: } 1.2 \%
\end{aligned}
$$

\begin{tabular}{|c|c|c|c|c|}
\hline$D-\mathrm{H} \cdots A$ & $D-\mathrm{H}$ & $\mathrm{H} \cdots A$ & $D \cdots A$ & $D-\mathrm{H} \cdots A$ \\
\hline $\mathrm{O} 72-\mathrm{H} 72 \cdots \mathrm{O} 2$ & $0.96(7)$ & $1.57(8)$ & $2.483(6)$ & $158(7)$ \\
\hline $\mathrm{O} 72-\mathrm{H} 72 \cdots \mathrm{O} 72^{\mathrm{i}}$ & $0.96(7)$ & $2.47(7)$ & $2.814(6)$ & $101(5)$ \\
\hline $\mathrm{N} 81-\mathrm{H} 811 \cdots \mathrm{O} 71^{\mathrm{ii}}$ & $0.99(5)$ & $1.96(6)$ & $2.912(7)$ & $160(6)$ \\
\hline $\mathrm{N} 81-\mathrm{H} 811 \cdots \mathrm{O} 72^{\mathrm{ii}}$ & $0.99(5)$ & $2.54(6)$ & 3.031 (7) & $110(4)$ \\
\hline $\mathrm{N} 81-\mathrm{H} 812 \cdots \mathrm{O} 2^{\mathrm{iii}}$ & $1.00(5)$ & $1.85(5)$ & $2.823(6)$ & $164(5)$ \\
\hline $\mathrm{N} 81-\mathrm{H} 812 \cdots \mathrm{O} 31^{\mathrm{iii}}$ & $1.00(5)$ & $2.51(6)$ & $3.081(7)$ & $116(4)$ \\
\hline 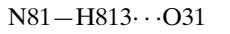 & $0.90(7)$ & $2.39(7)$ & $3.239(7)$ & $158(4)$ \\
\hline $\mathrm{N} 81-\mathrm{H} 813 \cdots \mathrm{O} 32$ & $0.90(7)$ & $2.47(6)$ & $3.125(7)$ & $130(5)$ \\
\hline $\mathrm{C} 71-\mathrm{H} 712 \cdots \mathrm{O} 52^{\mathrm{iv}}$ & 0.96 & 2.58 & $3.530(7)$ & 172 \\
\hline
\end{tabular}

\section{Refinement}

Refinement on $F^{2}$

$R\left[F^{2}>2 \sigma\left(F^{2}\right)\right]=0.056$

$w R\left(F^{2}\right)=0.217$

$S=0.88$

3406 reflections

234 parameters

$\mathrm{H}$ atoms treated by a mixture of independent and constrained refinement

\section{Table 1}

Hydrogen-bonding geometry $\left(\AA{ }^{\circ},{ }^{\circ}\right)$.

Symmetry codes: (i) $2-x, 2-y, 1-z$; (ii) $x-1, y, z-1$; (iii) $1-x, 2-y,-z$; (iv) $x, 1+y, z$.

$\mathrm{H}$ atoms involved in hydrogen-bonding interactions (H72, H811, H812 and H813) were located by difference syntheses and their
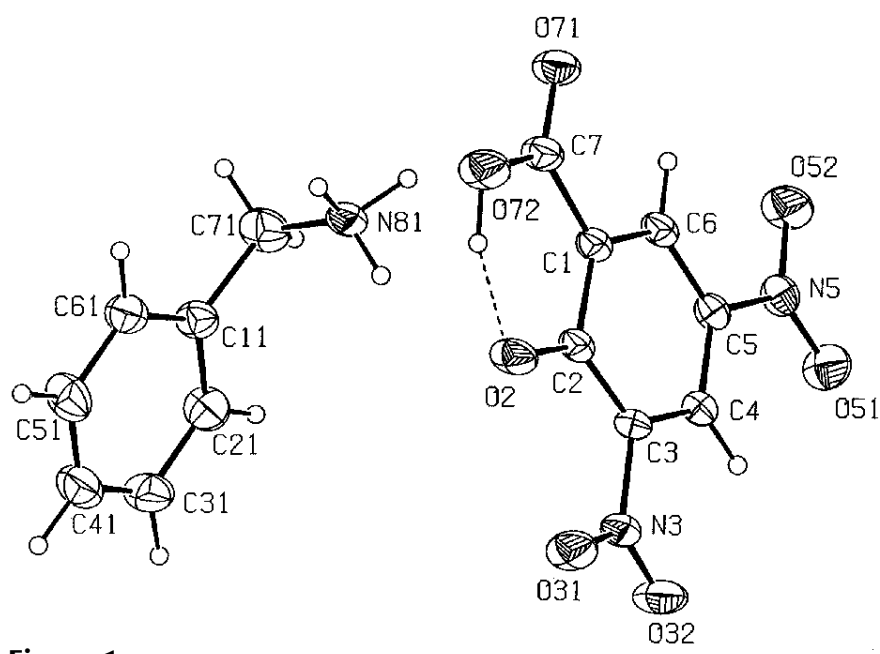

Figure 1

The molecular configuration and atom-labelling scheme for the individual anion and cation species in (I), with non-H atoms shown as $30 \%$ probability ellipsoids (Spek, 1999).

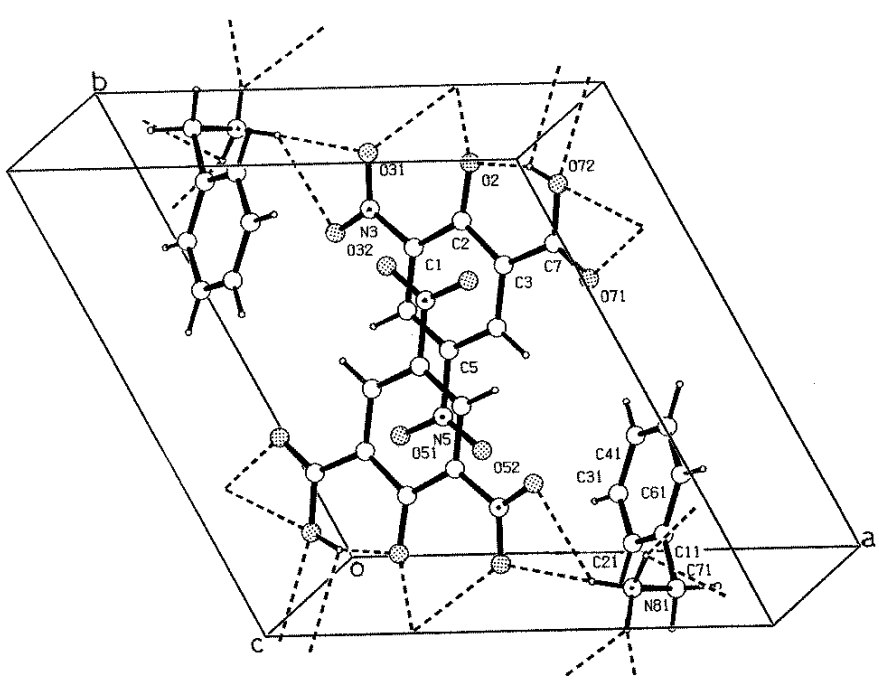

Figure 2

Perspective view of the packing in the unit cell, viewed down $c$, showing hydrogen-bonding associations as broken lines.

positional and isotropic displacement parameters were refined. Others $\mathrm{H}$ atoms were included in the refinement as riding models. For refined $\mathrm{H}$ atoms, the $\mathrm{N}-\mathrm{H}$ range is 0.90 (7)-1.00 (5) $\AA$; the intramolecular $\mathrm{O}-\mathrm{H}$ distance in the DNSA anion is 0.96 (7) $\AA$.

Data collection: MSC/AFC Diffractometer Control Software (Molecular Structure Corporation, 1999); cell refinement: MSC/AFC Diffractometer Control Software; data reduction: TEXSAN (Molecular Structure Corporation, 1999); program(s) used to solve structure: SHELXS97 (Sheldrick, 1997); $\operatorname{program}(\mathrm{s})$ used to refine structure: SHELXL97 (Sheldrick, 1997); molecular graphics: PLATON for Windows (Spek, 1999); software used to prepare material for publication: TEXSAN.

The authors acknowledge financial support from The Centre for Instrumental and Developmental Chemistry 


\section{organic papers}

(Queensland University of Technology) and Griffith University.

\section{References}

Kumar, V. S. S., Kuduva, S. S. \& Desiraju, G. R. (1999). J. Chem. Soc. Perkin Trans. 2, pp. 1069-1073.

Molecular Structure Corporation (1999). MSC/AFC Diffractometer Control Software and TEXSAN for Windows (Version 1.06). MSC, 9009 New Trails Drive, The Woodlands, TX 77381, USA.
Sheldrick, G. M. (1997). SHELXL97 and SHELXS97. University of Göttingen, Germany.

Smith, G., Bott, R. C., Wermuth, U. D., Healy, P. C. \& White, J. M. (2002). Aust. J. Chem. In the press.

Smith, G., Lynch, D. E., Byriel, K. A. \& Kennard, C. H. L. (1995). Aust. J. Chem. 48, 1133-1149.

Smith, G., Wermuth, U. D. \& White, J. M. (2001). Acta Cryst. E57, o1036o1038.

Spek, A. L. (1999). PLATON for Windows. Version of September 1999. University of Utrecht, The Netherlands. 